\title{
Analysis of Energy Consumption and Electricity Alternative Potential in Northern Hebei Province
}

\author{
Yonghua Wang ${ }^{1}$, Yue $\mathrm{Xu}^{2} \&$ Jia-Xin Zhang ${ }^{1}$ \\ ${ }^{1}$ School of Economics and Management, North China Electric Power University, Beijing, China \\ ${ }^{2}$ Nanchang Electric Power Trading Center Co., Ltd., China \\ Correspondence: Yonghua Wang, School of Economics and Management, North China Electric Power University, \\ Beijing 102206, China. Tel: 86-137-0709-3159. E-mail: 446836810@qq.com
}

\author{
Received: February 1, 2018 \\ Accepted: February 28, 2018 \\ Online Published: May 30, 2019 \\ doi:10.5539/eer.v9n1p23 \\ URL: https://doi.org/10.5539/eer.v9n1p23
}

The research is financed by Beijing Social Science Fund Energy Base Project "A Study on Clean Utilization and Development of Energy in Rural Area under Beijing-Tianjin-Hebei Coordinated Development"(17JDYJB011).

\begin{abstract}
The long-established coal-based energy structure and the development mode characterized by high input, high consumption and high emission in northern Hebei can hardly sustain. Electricity alternative is an effective way to optimize the energy structure and control pollution emissions. The paper analyzes the current situation of energy consumption structure and electricity alternative in northern Hebei. It shows that despite of many problems, electricity alternative in northern Hebei enjoys a huge potential.
\end{abstract}

Keywords: Northern Hebei, electricity alternative, policy, energy structure

\section{Introduction}

In recent years the northern Hebei (Tangshan, Langfang, Zhangiiakou, Chengde and Qinhuangdao) has been nagged by environment pollution and haze. The main causes include the coal-based energy structure and the highinput, high-consumption and high-emission development mode. Therefore the top priority for the government is to change the backward energy consumption structure, control the total energy consumption and minimize use of fossil energy such as coal and petroleum. Compared with the traditional energy such as coal, petroleum and natural gas, electric power is safe, clean and high efficient, and has obvious advantages in the conversion efficiency at the terminal consumption juncture. In order to reduce pollutant emission and promote clean and low-carbon development of the high-energy consumption and high-pollution industries, the Chinese government put forward to vigorously promote the policy of electricity alternative in the terminal consumption.

On May 16, 2016, eight commissions and ministries jointly issued the Guiding Opinions on Promoting the Electricity Alternative (Fa Gai Neng Yuan [2016] No.1054), Plan for Clean Heating in Winter in Northern Areas (2017-2022). In 2018, the central government set forth the Three-Year Blue Sky Protection Campaign (2018-2021), which provides a policy basis for comprehensively promoting the electricity alternative. Electricity alternative is to replace coal and oil with electric power in the terminal consumption, improve the fuel use efficiency and reduce pollutant emission through large-scale centralized conversion, thereby optimizing the terminal energy structure and promoting environmental protection. The electricity alternative includes substituting electric power for coal and petroleum and agricultural production electrification, among others. The substitute products cover heat pump, energy storage, electric boiler, electric furnace, electric heating, agricultural electric drainage and irrigation, shore power engineering, electric vehicle, rail transit and other technical fields. In order to establish a green energy consumption mode, build a clean, low-carbon, safe and high efficient energy system, the State Grid Corporation of China (SGCC) proposed to accelerate the transfer of grid development, and established the development strategy "substituting electric power for coal, petroleum and transmitting electric power from afar", comprehensively implementing the electricity alternative in energy production, transmission and consumption junctures. Such efforts can give play to advantages of convenience, safety, cleanness and high efficiency of electric power, continuously improve proportion of electric power in the terminal energy consumption and considerably optimize the energy structure. In 2017, SGCC and China Southern Power Grid jointly completed electricity alternative of 
128.6 billion $\mathrm{kWh}$, accounting for $2.0 \%$ of the total electric power consumption of China. It can be seen that electricity alternative has made a significant contribution to promoting air pollution control and energy transformation.

Currently northern Hebei has promoted the electricity alternative in fields such as electric vehicle, electric heating, electric boiler and port shore power. In order to promote effective implementation of electricity alternative, it is necessary to further analyze the potential of electricity alternative based on the regional consumption mode.

\section{Current Situation of Energy Consumption in Northern Hebei}

A good understanding of the current situation of energy consumption is a precondition for seeking opportunities for electricity alternative.

\subsection{Current Situation of Coal Consumption}

The coal consumption is mainly composed of six parts: urban residents' living, rural residents' living, agricultural production, commercial catering, public utilities, and industrial power, see Table 1 for details.

Table 1. Coal consumption in northern Hebei in 2016 (Unit: 10,000 tons)

\begin{tabular}{|c|c|c|c|c|c|c|c|}
\hline Type & Tangshan & Langfang & Zhangjiakou & Chengde & Qinhuangdao & \multicolumn{2}{|c|}{ Total ( \%) } \\
\hline Urban residents & 2.79 & 6.79 & 60.6 & 6.06 & 27.44 & 103.68 & $(1.2)$ \\
\hline Rural residents & 108.29 & 101.06 & 196.04 & 136.14 & 115.31 & 656.84 & $(7.9)$ \\
\hline Agricultural production & 2.01 & 1.21 & 3.86 & 4.15 & 11.05 & 22.28 & $(0.3)$ \\
\hline Commercial catering & 2.49 & 2.07 & 9.08 & 4.72 & 3.55 & 21.91 & $(0.2)$ \\
\hline Public utilities & 8.02 & 3.36 & 5.52 & 5.25 & 3.05 & 25.19 & $(0.3)$ \\
\hline Industrial power & 3255.13 & 1674.97 & 1518.85 & 727.98 & 314.85 & 7491.78 & $(90.1)$ \\
\hline Total & 3378.73 & 1789.46 & 1793.95 & 884.3 & 475.25 & 8321.69 & $(100.0)$ \\
\hline Proportion (\%) & 40.6 & 21.5 & 21.6 & 10.6 & 5.7 & 100.0 & \\
\hline
\end{tabular}

The statistics shows: in terms of the coal consumption in various cities, Tangshan accounted for $40 \%$, Langfang $21.5 \%$, Zhangjiakou 21.6\%, Chengde $10.6 \%$ and Qinhuangdao 5.7\%; in terms of the consumption items, the main consumer was industrial power, accounting for $90.1 \%$; followed by rural residents, accounting for $7.9 \%$, and the rest did not exceed 1\%. Obviously the industrial power and rural residents show greater potential for electricity alternative; Tangshan is a key area for the electricity alternative.

\subsection{Current situation of petroleum consumption}

See Table 2 for the gasoline and diesel consumption in northern Hebei.

Table 2. Petroleum consumption of five cities in northern Hebei in 2016 (Unit: 10,000 tons)

\begin{tabular}{|c|c|c|c|c|c|c|}
\hline $\begin{array}{l}\text { Total petroleum } \\
\text { consumption }\end{array}$ & Tangshan & Langfang & Zhangjiakou & Chengde & Qinhuangdao & Total \\
\hline Gasoline & 2.38 & 21.16 & 1.01 & - & 3.05 & 27.60 \\
\hline diesel & 15.21 & 8.16 & 9.53 & - & 5.17 & 38.06 \\
\hline Total & 17.59 & 29.32 & 10.54 & - & 8.22 & 65.66 \\
\hline Proportion (\%) & 26.8 & 44.6 & 16.0 & & 12.6 & 100.0 \\
\hline
\end{tabular}

Note: As Chengde is a city with tourism as the pillar industry, its consumption of gasoline and diesel is not included in the table. 
As shown in Table 2, Tangshan, Langfang, Zhangjiakou and Qinhuangdao totally consumed 656,600 tons of petroleum, and Langfang accounted for $44.6 \%$, ranking the first.

\subsection{Current Situation of Natural Gas Consumption}

When collecting the natural gas consumption data, only Tangshan, Langfang and Qinhuangdao made statistics of natural gas consumption of industries above statistical threshold. See Table 3 for the natural gas consumption

Table 3. Natural gas consumption in northern Hebei (Unit: 100 million cubic meters)

\begin{tabular}{lllllll}
\hline Total natural gas consumption & Tangshan & Langfang & Zhangjiakou & Chengde & Qinhuangdao & Total \\
\hline Total & 8.00 & 2.10 & - & - & 0.11 & 10.21 \\
\hline
\end{tabular}

Tangshan, Langfang and Qinhuangdao totally consumed 1.021 billion cubic meters of natural gas in total, and Tangshan was the largest consumer.

\subsection{Energy Consumption Structure}

As the coal, petroleum and natural gas consumption is measured with 10,000 tons, 10,000 tons, and 100 million cubic meters as the unit respectively, it is necessary to transfer them into the standard coal measurement to analyze the energy consumption structure. The calculation formula for conversion to standard coal is as follows:

$$
\text { Standard coal }=\text { fuel consumption } x \text { Q/29274 }
$$

In Formula (1), Q stands for the lower calorific value, unit kilojoule (KJ).

After statistical calculation, the energy consumption and their proportion in northern Hebei are shown in Table 4.

Table 4. Coal, petroleum and natural gas consumption and composition in northern Hebei (Unit: 10,000 tons standard coal)

\begin{tabular}{|c|c|c|c|c|c|c|c|}
\hline Total consumption & Tangshan & Langfang & Zhangjiakou & Chengde & Qinhuangdao & Total $(\%)$ & \\
\hline Coal consumption & 2413.43 & 1278.21 & 1281.42 & 631.66 & 339.47 & 5944.18 & (96.3) \\
\hline $\begin{array}{l}\text { Petroleum } \\
\text { consumption }\end{array}$ & 25.13 & 41.89 & 15.06 & - & 11.74 & 93.80 & $(1.5)$ \\
\hline $\begin{array}{l}\text { Natural } \\
\text { consumption }\end{array}$ & 106.40 & 27.93 & - & - & 1.46 & 135.79 & $(2.2)$ \\
\hline Proportion (\%) & 41.0 & 22.0 & 21.0 & 10 & 6.0 & 6173.77 & $(100.0)$ \\
\hline
\end{tabular}

As shown in Table 4, coal consumption accounts for $96.28 \%$, which is absolutely the highest. From the perspective of regional consumption, Tangshan accounts for $41 \%$, Langfang $22 \%$, Zhangjiakou $21 \%$, Chengde $10 \%$, and Qinhuangdao 6\%. Tangshan ranks first in the energy consumption in northern Hebei.

\section{Current Situation of Electricity Alternative}

\subsection{Information about Major Electricity Alternative Projects}

In northern Hebei, the electricity alternative technology covers electric boilers, heat pumps, electric furnaces, heating cables, electric vehicles, and electric cold storage; seven emerging electricity alternative technologies are being promoted, including conveyor belt transmission, oil field electric drilling, pipeline electric pressure, port shore power, ore crushing, shaft oil-to-electric power transformation, and electric air compressors. In addition, two new electricity alternative technologies are developed, namely electromagnetic heaters and chillers.

In 2017, the State Grid Jibei Electric Power Company (Jibei Power Grid) totally promoted 2,845 electricity alternative projects, including 2,310 electric boiler projects, which achieved 600 million $\mathrm{kWh}$ of electricity alternative; 766 electric furnace projects, achieving 4.51 billion kWh of electricity alternative; 46 electric cold storage projects, achieving 170 million kWh of electricity alternative; 15 rail transit projects, achieving 685 million $\mathrm{kWh}$ of electricity alternative; and established 73 EV charging/battery swap stations, which have 506 charging piles and achieve 123 million kWh of electricity alternative. The other electricity alternative technologies realized 
electricity alternative of 6.011 billion $\mathrm{kWh}$.

\subsection{Overview of Supporting Power Grid Construction}

In 2016 and 2017, northern Hebei saw new expansion of planned $110 \mathrm{kV}$ line of 2,859 km, newly added substation capacity of 9,540 MVA, of which the total investment reached RMB7.436 billion; expansion of the planned $35 \mathrm{kV}$ line of $2,732 \mathrm{~km}$, increase of the substation capacity by 3,510 MVA, of which the total investment reached RMB2.495 billion. The planned $10 \mathrm{kV}$ and below lines increased by $6,578 \mathrm{~km}$, which newly added substation capacity by 5,310 MVA, and had a total investment of RMB9.033 billion. During the $12^{\text {th }}$ Five-Year Plan period, the total planned new line increased by $12,169 \mathrm{~km}$, and the newly added substation (distribution) capacity reached 18,360 MVA, with a total investment of RMB18.96 billion.

\subsection{Existing Problems in Electricity Alternative}

There are following problems in the electricity alternative:

First, traditional energy consumption concepts. Most energy consumers hold the traditional energy consumption concepts, and have insufficient understanding to the electricity alternative. Though electric power can make production and living environment cleaner[58], and effectively improve the air quality and control haze, energy consumers would normally first choose the energy with the lowest cost and neglect the hidden value such as environmental costs, if there is not a mandatory restriction policy. From the perspective of the terminal energy consumption structure, the proportion of non-electric power consumption is still high. As a clean energy, electric power has a large room to improve its proportion in the terminal energy consumption. Therefore, it is necessary to further strengthen research on electricity alternative technology, enhance publicity and guidance, and increase policy support and subsidies to develop awareness and a favorable social environment for the use of clean energy.

Second, the electricity alternative technology remains to be further improved. Compared with the traditional fossil energy, electric power does not have high economic advantages. Factors such as the cost of electricity alternative projects, power distribution facilities, and electricity bill may result in weaker economical efficiency of the electricity alternative projects. In the process of promoting electricity alternative technology, the electricity alternative projects show little obvious advantages in various fields due to the relatively high cost of the electricity alternative technology. The application of electric heating technology brings users high investment and operating costs while there is not much practical results in electrical efficiency in electric vehicles and shore power technology. Therefore, the electricity alternative technology needs to be further improved.

Third, power grid construction still needs to be strengthened. In the peak season of power consumption, northern Hebei still adopts the orderly electric power consumption measures, which will affect the capacity of meeting the demand of a large number of electricity alternative projects. In addition, the distribution network structure in rural areas is relatively weak, and most of the urban areas adopt the central heating. Therefore, the rural area will be the key areas for the electricity alternative technology such as "substituting electric power for coal", which will further increase burden of the rural distribution network. The existing rural power grid upgrade and transformation needs to further keep up with the pace of the load growth, so as to avoid bottleneck of not meeting the needs of electricity alternative in rural areas.

Fourth, the policy support and management system needs to be improved. In recent years, governments at all levels have gradually accepted the electricity alternative, and introduced some encouragement policies, which provide strong support for the implementation of electricity alternative in fields like electric vehicle, heat pump and coalfired boiler. However, the government supports for the electricity alternative policy are still not enough. There are not supporting policies in the fields such as fiscal subsidy, tax reduction, and support inputs, or some existing subsidy and incentive policies are difficult to implement. When customers choose equipment, the electricity alternative equipment show little obvious comprehensive comparative advantage. Collaboration and management capabilities need to be improved. The electricity alternative is a complicated management process, which requires the participation of the government, the power grid enterprises and the energy consumers to form an integrated work force, develop an integrated, full-coverage and all-round work pattern to serve the electricity alternative.

\section{Opportunities for the Electricity Alternative}

\subsection{Incentive Policies for Electricity Alternative}

A series of regulations and action plans have been promulgated, including the Air Pollution Prevention and Control Action Plan, Detailed Rules of Beijing, Tianjin, Hebei and Neighboring Areas for the Implementation of the Air Pollution Prevention and Control Action Plan, Work Plan for Strengthening the Air Pollution Prevention and Control of the Energy Industry, Circular of the State Council on Printing and Distributing the Development Plan for the Energy Conservation and New Energy Vehicle Industries (2012-2020), which all clearly stated to vigorously 
support application and promotion of the electricity alternative technology to improve the environment. The coordinated development of Beijing, Tianjin and Hebei also provides a favorable condition and important opportunities for the electricity alternative. Hebei provincial and local governments issued actions plans and implementation plans for the air pollution prevention and control to promote the energy consumption structure improvement and accelerate the energy transformation.

\subsection{Increasingly Strengthened Power Supply Security}

As the main energy source for electricity alternative, the power supply security is critical. The economic aggregate in the northern Hebei is relatively large and the energy consumption is huge, but the power resources are relatively limited. In the peak load period, the orderly electric power utilization and pre-plans are often adopted and the power supply is short. The Jibei Power Grid has accelerated the construction of Zhangbei-Nanchang AC UHV Project in the new round of clean energy development. This provides good conditions for power supply and electricity alternative.

\subsection{Price Reduction Brings Opportunities for Electricity Alternative}

The Notice on Lowering the Coal-fired Power On-grid Price and Price of Electric Power for General Industrial and Commercial Users of Hebei Provincial Price Bureau (Ji Jia Guan [2015] No.308) was enacted on January 1, 2016, which reduced the on-grid price of coal-fired generating units in Hebei, and the price of electric power for general industrial and commercial users. The price of electric power for general industrial and commercial users and others (excluding chemical fertilizer production) in Jibei Power Grid was reduced by 3.1 cents. It has realized the same price in the same grid for agricultural production. The electric power price for non-poverty agricultural production under the rural comprehensive transformer of Jibei Power Grid is RMB0.6064, and for poverty-stricken county RMB0.4584. The price reduction has provided conditions for vigorously implementing electricity alternative, promoting enterprise power use innovation and increasing the proportion of electric energy in the terminal energy consumption market.

\subsection{Better Renewable Energy Resources in Northern Hebei Provide Good Prospects for Energy Replacement}

Hebei Province is rich in wind resources and widely distributed solar energy resources.

The abundant wind resources in Hebei Province are mainly distributed in Zhangjiakou, Chengde and Taihang Mountains, and Yanshan Mountains. Its development resources are shown in Table 5.

Table 5. Development of wind energy resources in Hebei

\begin{tabular}{lll}
\hline Province (Municipality) & Technical exploitability $/ \mathrm{MW}$ & Technically exploitable area $/ \mathrm{km}^{2}$ \\
\hline Hebei & 11980 & 3466 \\
\hline
\end{tabular}

Compared with Beijing and Tianjin, Hebei Province has certain advantages in solar photovoltaic resources, as shown in Table 6.

Table 6. Distribution of solar energy resources

\begin{tabular}{|c|c|c|c|}
\hline Province(Municipality) & Average sunshine $(\mathrm{h})$ & $\begin{array}{l}\text { Total amount of radiation } \\
\left(\mathrm{MJ} \cdot \mathrm{m}^{-2}\right)\end{array}$ & Resource category \\
\hline Beijing & $2600 \sim 3000$ & $5000 \sim 6000$ & Class II \\
\hline Tianjin & $2471 \sim 2769$ & 5610 & Class III \\
\hline Northern Hebei & $3000 \sim 3200$ & $5852 \sim 6680$ & Class II \\
\hline Southern Hebei & $2200 \sim 3000$ & $5016 \sim 5852$ & Class III \\
\hline
\end{tabular}

The development and utilization of renewable energy resources in northern Hebei has a very broad prospect for the replacement of electric energy.

\subsection{Incentive Policies for Electricity Alternative}

At present, electric furnace, port shore power, heat pump, electric energy storage, carbon crystal heating and other 
technologies have already showed good economical efficiency and popularization and application value. In the future, with the continuous improvement of technology and the gradual implementation of policies, electricity alternative technology will be more widely used.

\section{Conclusion}

This paper analyzes the current situation of energy consumption and structure in northern Hebei. As coal takes a lion's share in the energy consumption, it can be concluded that "coal-to-electric power" will be the key for implementing electricity alternative in northern Hebei, which boasts a huge potential. At the same time, Tangshan is a major energy consumer, and it has the highest potential and is bound to be the key area for electricity alternative. There are still many problems for the implementation of the electricity alternative: traditional energy consumption concepts, economic efficiency and supporting facilities of electricity alternative technology need to be further improved, and so is the policy support system. The electricity alternative is a major way for China to save energy and reduce emission, and enjoys a great potential in the future development.

\section{References}

Xu, X. G. (2017). Current situation, problems and countermeasures of new energy development and utilization in Hebei province. Statistics and Management, 38(1), 123-125.

Zhang, X. H., Yang, Y. F., \& Zhou, P. C. (2018). Research on new energy development in Beijing-Tianjin-Hebei region. Environmental Engineering, 36(7), 179-184. https://doi.org/ 10.13205/j.hjgc.201807036

\section{Copyrights}

Copyright for this article is retained by the author(s), with first publication rights granted to the journal.

This is an open-access article distributed under the terms and conditions of the Creative Commons Attribution license (http://creativecommons.org/licenses/by/4.0/). 